\title{
A Graphical Workstation Based Part-Task Flight Simulator for Preliminary Rapid Evaluation of Advanced Displays
}

\author{
C. Wanke, J. Kuchar. E. Hahn, A. Pritchett, and R. J. Hansman \\ Department of Aeronautics and Astronautics \\ Massachusetts Institute of Technology \\ Cambridge. MA USA
}

\begin{abstract}
Advances in avionics and display technology are significantly changing the cockpit environment in current transport aircraft. The MIT Aeronautical Systems Lab (ASL) has developed a part-task flight simulator specifically to study the effects of these new technologies on flight crew situational awareness and performance. The simulator is based on a commercially-available graphics workstation, and can be rapidly reconfigured to meet the varying demands of experimental studies. The simulator has been successfully used to evaluate graphical microburst alerting displays, electronic instrument approach plates, terrain awareness and alerting displays, and ATC routing amendment delivery through digital datalinks.
\end{abstract}

\section{INTRODUCTION}

The implementation of advanced technology has significantly changed the cockpit environment in current "glass cockpit" aircraft. Recent developments in display technology. on-board processing. data storage, and datalinked communications are likely to further alter the environment in second and third generation "glass cockpit" aircraft. It is important that these technologies be implemented in a manner which will enhance both the human and systems performances, in terms of both safety and efficiency. Because many of the changes in cockpit technology center around information management, proper design of advanced cockpit systems requires careful consideration of the human performance issues, particularly in the cognitive domain.

The MIT Aeronautical Systems Lab (ASL) has developed a part-task flight simulator specifically to study these issues. The simulator, based on a commerciallyavailable graphics workstation, replicates the Electronic Flight Instrumentation System (EFIS). Flight Management Computer (FMC), and primary autoflight systems of a modem "glasscockpit" aircraft such as the Boeing $757 / 767$ or $747-400$. Topics studied using this simulator include graphical displays for hazardous weather information, terrain awareness and alerting displays. datalink of ATC clearance amendments, and electronic approach plates.

The simulator provides high fidelity representations of electronic autoflight and instrumentation systems while remaining low-cost, rapidly reconfigurable, and portable enough to move to altemate sites if necessary. It allows new displays to be d.' eloped quickly and evaluated through night simulations with active airline pilots of electronic cockpit aircraft. This paper discusses the design, advantages, and limitations of this approach.

\section{DESIGN OBJECTIVES AND REQUTREMENTS}

The design of the MIT Advanced Cockpit Simulator was motivated by the need for preliminary evaluation of new cockpit information systems. The primary area of interest is the effect of these new systems on human cognitive performance. This area includes such issues as information transfer efficiency, pilot decision-making performance. and flight crew situational awareness.

To evaluate cognitive performance issues, the autolight systems and primary displays which affect decision-making needed to be simulated as exactly as possible. In addition, the need to test many different prototype displays demanded rapid reconfigurability. These requirements were achieved by simulating the graphical displays on a commercially-available graphics workstation. The simulation software was written by the researchers in modular fashion so that different displays could be implemented by recoding or replacing the appropriate modules.

A further requirement was simplicity. Since only cognitive-level issues were to be evaluated, it was assumed that all aircraft control would be performed using autoflight systems. Therefore, the autoflight and flight management systems needed to be simulated, but the direct flying controls (stick, rudder, throttles, etc.) could be omitted. For this reason no special hardware was required beyond general-purpose computers and some simple control panels, greatly reducing development time and simulator set-up time.

This simplicity also defines the limitations of this approach. Experiments involving flying performance. two- or three-man crews, or requiring a full coclpit workload situation are not practical with this simulator. However, this part-task approach can be useful for preliminary evaluation of candidate displays or procedures before a full-mission simulation is attempied.

Research supported by government grant. 


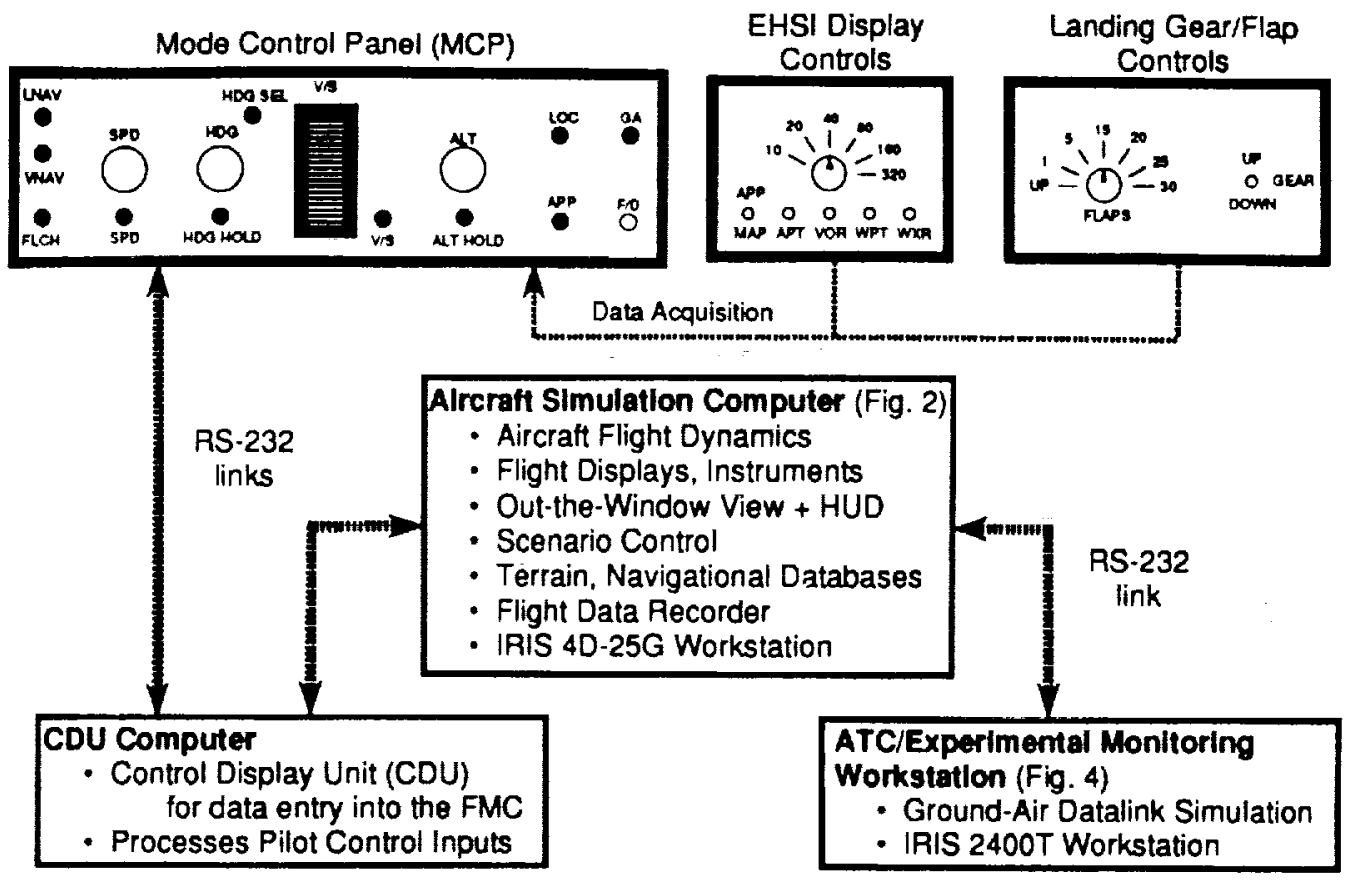

Figure 1: MTT ASL Advanced Cockpit Simulator. The simulator includes three computers and some auxiliary control panels, connected by standard RS-232 serial links.

\section{IRIS 4D25-G Workstation Display}

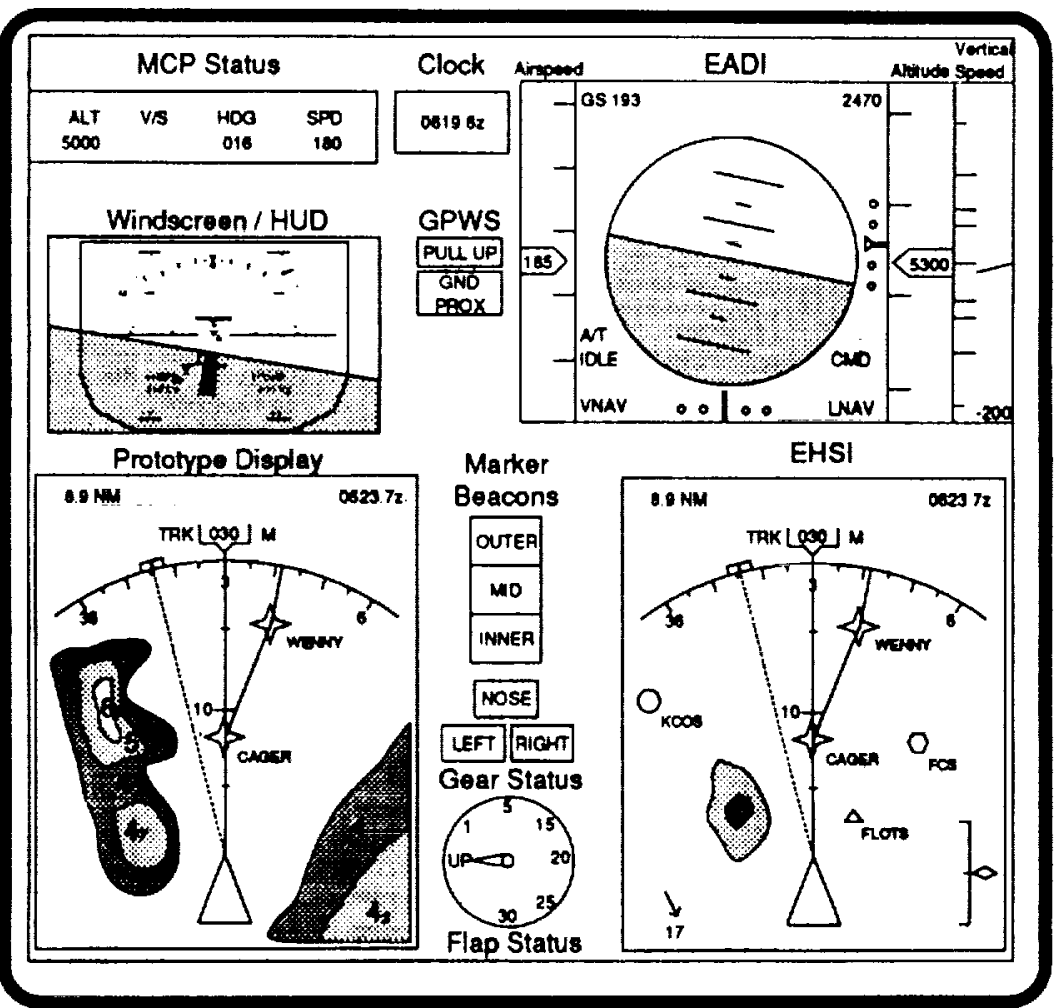

Fgure 2: Primary Flight Instrumentation. This is a schematic view of the IRIS 4D-25G display in a typical configuration. Note tha the electronic displays are actually in color on the simulator. 


\section{THE MIT ADVANCED COCKPIT SIMULATOR}

OVERVIEW - As shown schematically in Figure 1, the full version of the MIT ASL Advanced Cockpit Simulator facility utilizes three computers and several control panels to emulate cockpit displays, autoflight systems, and Air Traffic Control (ATC). A Silicon Graphics IRIS 4D-25G graphics workstation is used to display the cockpit instruments (Figure 2) and compute flight dynamics. The Control Display Unit (CDU) is emulated by an IBM-XT computer, and a Silicon Graphics 2400T workstation is used as an Air Traffic Control workstation (Figure 4). The portable version of the simulator omits the ATC workstation. Pilot input through the control panels is detected by the IBM-XT through a data acquisition unit. All three computers exchange data through standard RS. 232 serial communication links.

The simulator's cockpit displays are based on current "glass-cockpit" aircraft such as the Boeing $757 / 767$ and 747 400. The IRIS screen depicts two major cockpit displays, the Primary Flight Display (PFD) and Electronic Horizontal Situation Indicator (EHSI). along with several secondary displays. Additional displays can be rapidly prototyped and added to the simulator for evaluation. The nominal flight displays may then be rearranged or modified to accommodate the new displays as needed.

Airspeed. altitude, and vertical speed are indicated on the PFD using moving tape displays similar to those found on the B747-400. An Electronic Altitude Director Indicator (EADI) displays the artificial horizon, ground speed, radio altitude, and Instrument Landing System (ILS) localizer and glideslope deviations.

The EHSI is located below the PFD, as in the B757 or 767. The EHSI is the primary navigational instrument, and the simulator version is based on the map mode used in the B757/767. It includes information such as aircraft heading, ground track. FMC-programmed route, nearby airports and navaids, and wind information. Weather radar returns can also be displayed. A control panel is provided for setting the EHSI display range (10 to $320 \mathrm{~nm}$ ) and for suppressing weather radar returns or off-track intersections. navaids, or airports. Flap. gear, and marker beacon light displays are provided to the left of the EHSI. Controls allow the pilot to set the flaps and lower or raise the landing gear during the approach. Additional controls such as a manual pressurization valve can be added to the simulation if a side task is necessary to increase the ambient crew workload.

A simple perspective out-the-window view is provided as a means by which to cue the pilod that the aircraft has descended below the cloud deck. While in instrument conditions, the display appears gray. Below the cloud deck. a perspective view of the airport appears.

A Head-Up Display (HUD) is also available.

implemented over the out-the-window view (Figure 3). It uses symbology similar to that used on a commercially available HUD from Flight Dynamics. Inc. Roll, pitch, and heading scales as well as a flight path symbol are displayed in perspective format. Numeric information includes barometric altitude, airspeed, ground speed, vertical speed, and wind information.

AUTOFLIGHT AND FLIGHT MANAGEMENT SYSTEMS - The CDU for entry of flight path information into the Flight Management Computer (FMC) is simulated with an IBM-XT computer. Several screen displays, or "pages", can be selected: The Route page to select a destination, the Legs page to select waypoints and vertical path constraints, and the Direct-To page to change the immediate waypoint. The CDU is linked to the EFIS so that active and modified roules are displayed both textually, on the CDU, and graphically. on the EHSI. At first, the CDU interface used a standard computer keyboard and monochrome monitor. At this time. a replica of the $757 / 767 \mathrm{CDU}$ display and keyboard is being integrated into the system to enhance realism.

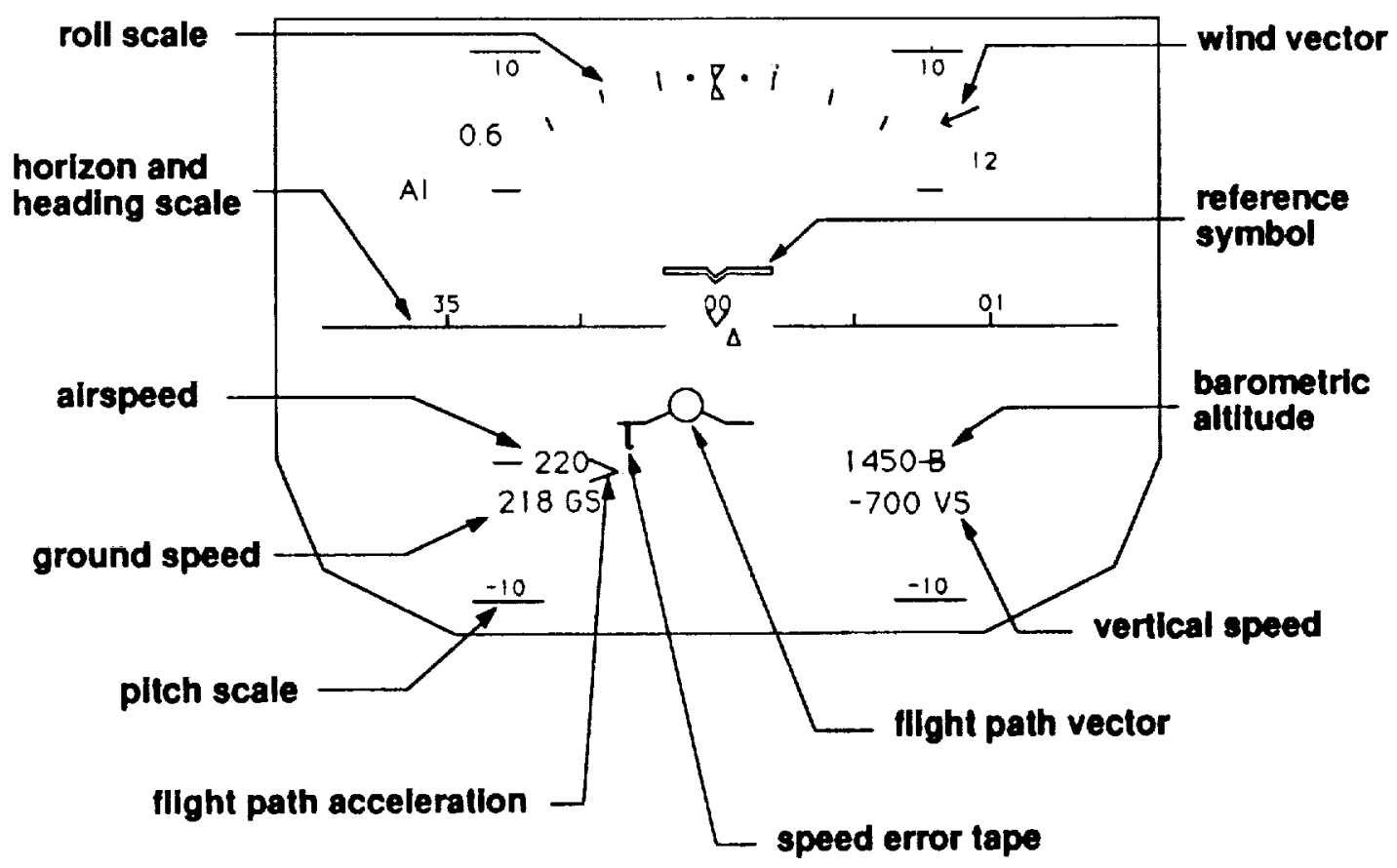

Figure 3: Head-Up Display (HUD). The HUD is overlaid on the windscreen, as seen in Figure 2. 
IRIS 2400T Workstation

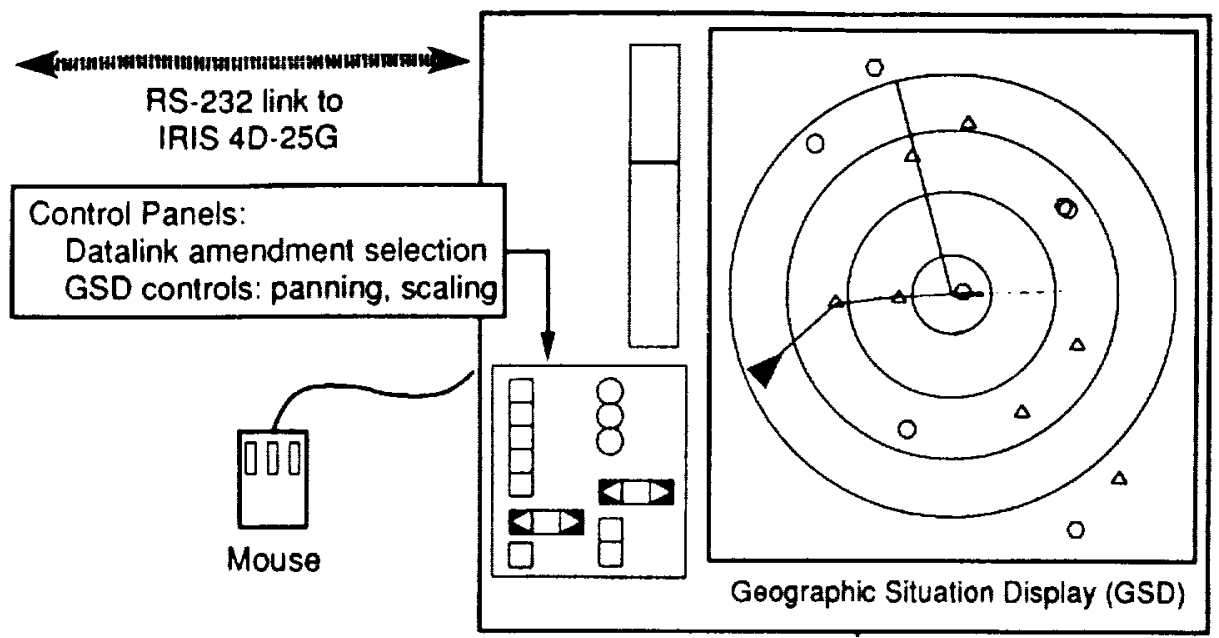

Figure 4: ATC/Experimental Control Workstation Display. The Geographic Situation display provides an airport-centered view of the scenario region, including the position of the simulator aircraft. It can be panned and rescaled by the simulation controller.

Non-FMC control of the aircraft is performed through an autopilot Mode Control Panel (MCP), similar to that used on the Boeing 757/767. A standard set of autothrottle and autoflight modes are available, including LNAVNNAV flight (following FMC-programmed lateral and vertical flight paths) and the various capture ("select") and hold modes for airspeed. heading, vertical speed, and altitude. It is also possible to engage localizer and glideslope capture modes and a goaround mode for missed approaches.

AIRCRAFT DYNAMICS - The basic aircraft flight dynamics are based on longitudinal point-mass equations of motion in wind axes, and simple decoupled first-order roll angle dynamics. The aircraft data used (provided by NASA Langley Research Center, and used in [1]) is for a Boeing 737. 100 aircraft, and includes non-linear curve fits for $C_{L}$ and $C_{D}$ as functions of angle-of-attack, flap position, and gear position. The multivariable inner-loop controller designed for this model took the form of a fully-coupled proportional-plusintegral cascade compensator and allows the aircraft to follow airspeed, flight path angle, and heading commands from the autoflight systems.

The autoflight systems provide outer loop control inputs and can operate in several different modes, ranging from simple altitude or heading holds up to full lateral and vertical path guidance based on the FMC programmed route. Localizer and glideslope tracking modes can be engaged for final approach. Because outer-loop controllers for the various autoflight modes are based on approximate frequencies and damping ratios for the Boeing 767 aircraft control system [2], the aircraft responds like a 767 when being controlled through the autoflight systems.

For the experiments including microburst wind shear events, a wind model is available including both constant wind components and simulated microburst winds from an analylical model [3].

ATC/EXPERIMENT CONTROL WORKSTATION The ATC workstation (Figure 4) is used to monitor the progress of the aircraft's flight and to issue simulated datalink ATC clearance amendments. A mouse-based graphical user interface provides the ability to select and deselect navigational information determine the aircraft location relative to a scenario reference point, and select and specify content and format of the scripted ATC messages. The controller is in contact with the pilot through a wireless headset. to simulate a standard $\mathrm{VHF}$ radio link. Simulated datalink messages are transmitted from the ATC workstation to the simulation computer via a serial communications link. It should be noted that this display was not intended to reproduce any actual or proposed advanced ATC workstation; it was designed only for simulation control. RAPID PROTOTYPING CAPABILITIES - Commercially available display protolyping software was not used in order to reduce computational overhead. Instead, the night displays were created using software written in the $C$ programming language with IRIS Graphics Library primitives. This method of implementation allows flight displays to be rapidly reconfigured or redesigned to meet the varying demands of experimental studies. Typically, new displays may be created and added to the simulator in a matter of days.

Additional software was written to enable rapid creation of object-based charts for use with Electronic Instrument Approach Plate studies. Since a detailed object database was not available for use in the Advanced Cockpit Simulator. a software package was developed for the IRIS which facilitated the flexible, rapid creation of new chart display formats [4]. The program, called Map, allows the user to interactively create and modify electronic charts. Information may be grouped together in object-oriented layers which are then selectable by the pilot when flying the simulator. Also, a mouse-driven program called WxrEdit was developed to draw simulated weather radar reflectivity retums.

Scenarios can be set up and rapidly changed via English- language input files, which are read by the simulator software upon startup. These files define the starting aircraft position and state, pre-programmed FMC information, and scripted events to take place during a run. Scenario files also indicate Map and WxrEdis files to be loaded at start and during the runs.

\section{EXPERIMENTAL PROCEDURES}

In a typical experimental set up, an experimenter acting as air traffic controller is stationed at the ATC/Experimental Control Station and is in contact with the pilot through a simulated VHF link. The controller monitors the progress of the flight and issues vectors and approach clearance amendments according to a script for each scenario.

A second experimenter, acting as the Pilot Not Flying (PNF), is seated next to the subject pilot. In most experiments, the PNF experimenter handles ATC communications and is available to answer any questions about the simulator that occur during the experiment.

The cockpit is videotaped during the experiment to 
record ATC and intra-cockpit communications and actions. In addition, the simulator software records all flight data and pilot control inputs for the entire experimental run.

In order to maximize the validity of the results and minimize simulator training requirements, the subject pool is normally limited to professional air carrier pilots currently qualified on autoflight aircraft.

A typical session begins with the pilot completing a brief background questionnaire. The experiment is described briefly. and the subject is introduced to the simulator displays and controls. Practice flights are flown until the pilot feels comfortable with the control of the simulator and its displays. Finally. the pilot is asked to ny the simulator as responsibly as he or she would on a normal flight. and to feel free to request different or additional vectors from ATC, should the need arise.

When the pilot is ready to begin, the appropriate Instrument Approach Plates and charts are issued. Airport information (ATIS) is also given to the pilot to describe weather conditions and other information usually received before an approach. Scenarios typically begin $5010150 \mathrm{~nm}$ from the destination airport with an initial route programmed into the aircraft's FMC and displayed on the EHSI.

After the pilot reviews the charts and feels comfortable with the situation. the simulation is started. Amendments to the programmed route are issued by the air traffic controller and the pilot may control the aircraft through the Mode Control Panel or by programming the FMC through the CDU. A typical test matrix would require that each pilot fly 9 to 12 descent-and-approach scenarios. Most experimental scenarios are set in the terminal area when the flight crew is busiest and handles the most information. The entire session takes three to four hours to complete.

When possible, the independent variables in each study are counterbalanced to reduce leaming effects. Implicit measures of display efficacy are obtained by observing pilot reactions to scripted events that occurred during the flight. such as a vector into weather or a graphical microburst alert. In addition, subjective data is obtained through interviews with pilots both during and after the experiment.

\section{SURVEY OF SIMULATOR EXPERIMENTS}

Several studies involving cockpit information management have used the part-task simulator facility. The following list is a very brief description of several recent projects, which highlight the advantages of the simulator; the authors or references should be consulted for complete details on the experimental methods and results. Note that the figures in this section are schematic line drawings of color displays. and therefore lack some of the detail present on the aclual displays.

Gmohical microburst alertine displays. [5] Several different candidate displays for presenting microburst alerts were evaluated with the simulator (Figure 5). The rapid protolyping feature of the simulator was particularly useful in this study for design of several candidate displays. Also, the simulator was moved by van in order to do the experiment in a city with both an available facility and a large subject population, highlighting the advantage of portability.

Electronic instrument approach plates. [6] The advent of electronic library systems has made it possible to present charts electronically in the cockpit. This experiment compared several different possible formats and issues for electronic instrument approach plates (EIAP). The Map software

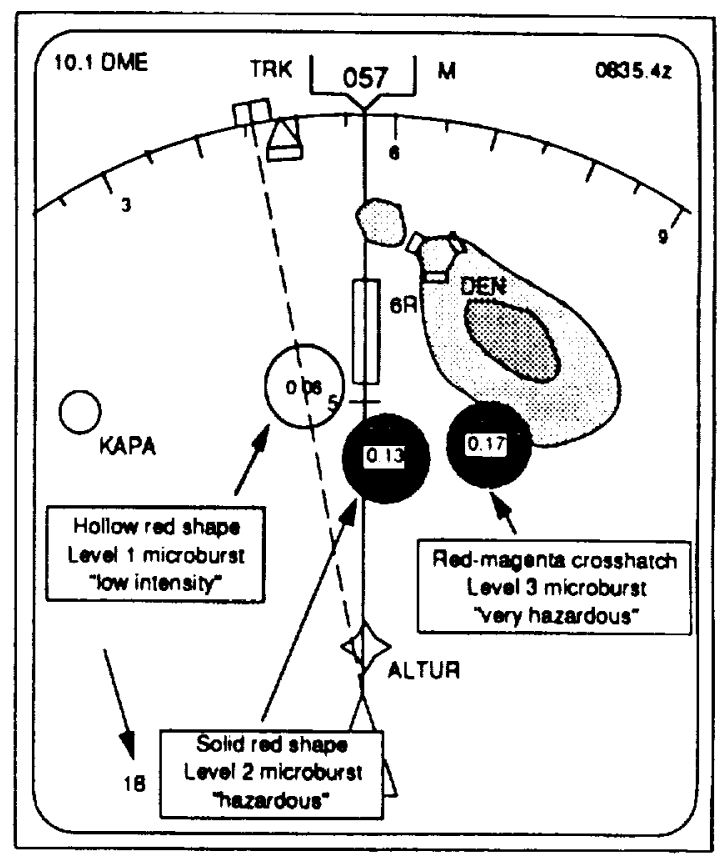

Figure 5: Graphical Mkroburst Alerting Display. Mictoburst alert icons are displayed directly on the EHSI display.

package was used to rapidly design these chart formats (Figure 6), which were then loaded and displayed by the simulator software. Chart information is grouped by type into layers, which can be selected or suppressed by the pilot with a switch panel similar to the EHSI control panel.

Terrain awareness displays. [7] Another application of electronic library systems is the presentation of terrain information, either as part of a ground proximity waming system or as a situational awareness display. One possible terrain awareness display (Figure 7) could present shaded contours. This display was also produced by the Map software, and was compared to more traditional spol elevation terrain representations in a piloted simulator study.

Graphical ATC datalink amendments. [8] The delivery of ATC clearance amendments through a digital air-ground datalink holds the potential to reduce voice congestion and information transfer errors associated with VHF radio communications. The ATC workstation (Figure 4) is linked directly with the FMC and the IRIS workstation to send datalink messages in either textual or graphical modes. and can direculy reprogram new routings into the FMC if required. An experiment compared the effects of several types of datalink ATC amendment presentations on flight crew situational awareness. Figure 8 shows a datalink ATC amendment which has been delivered and displayed on the EHSI.

Topics for future experiments include HUDs, displays for airbome forward-looking wind shear sensors, continued study of terrain avoidance displays, and study of applications of digital ground-air datalinks. 


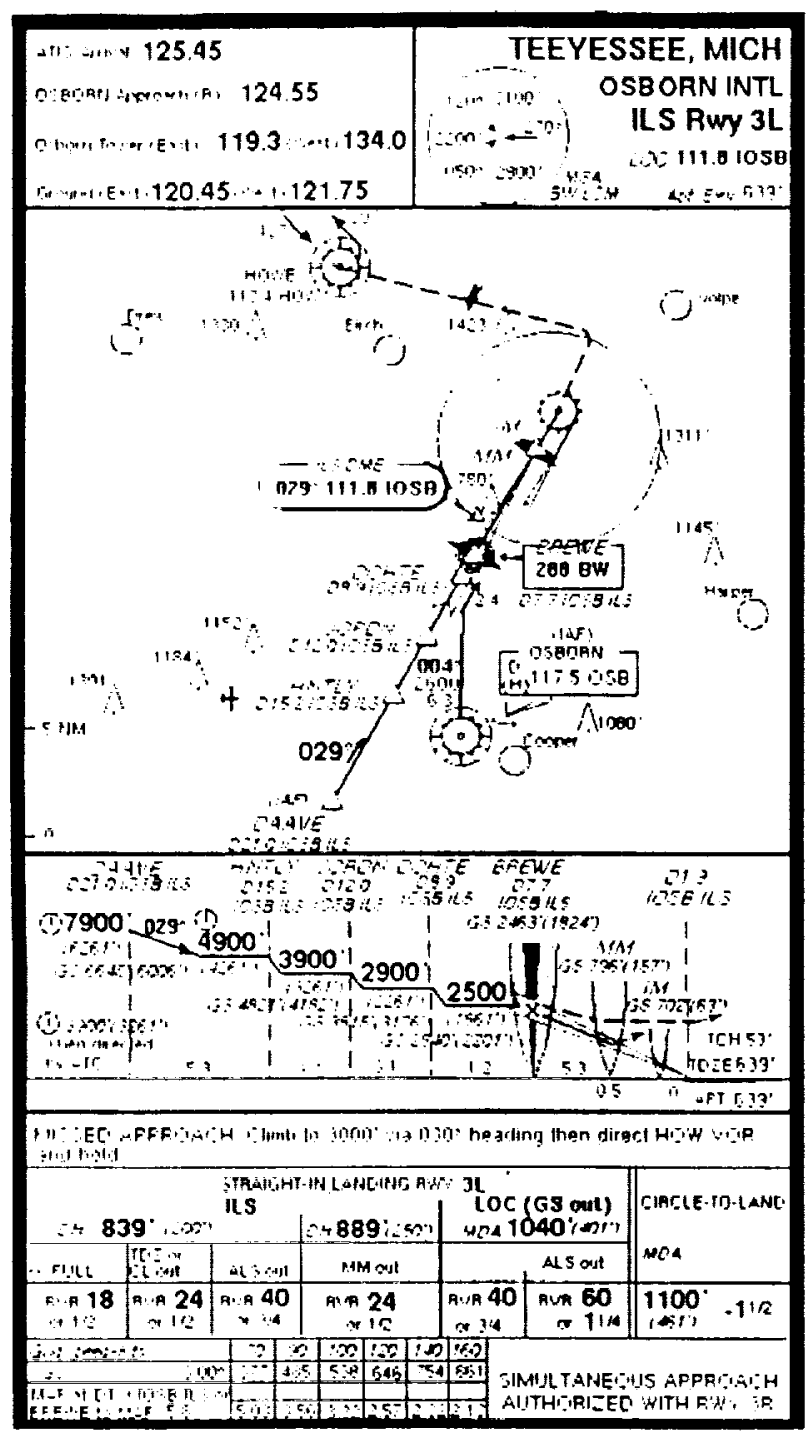

Figure 6: Sample Electroak Instrument Appronch Plate (ELAP) format. On this display, information is grouped into color-coded layers and can be hidden or selected by the pilot.

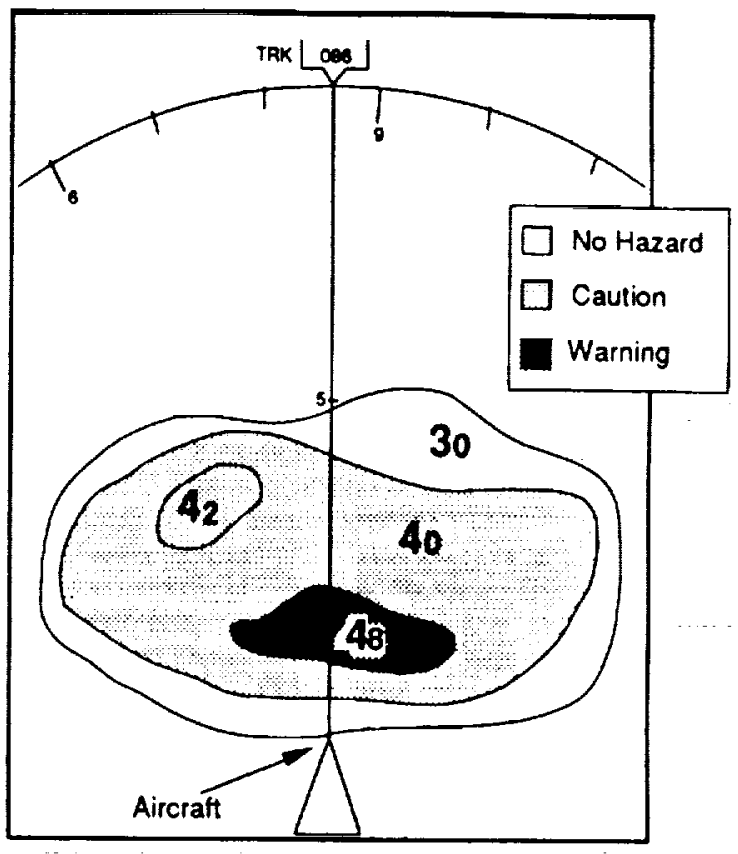

Figure 7: Contour Terrain Awareness Display with Graphical Ground Proximity Warning System (GGPWS). Terrain contours change to yellow or red colors when alerting criteria are satisfied.

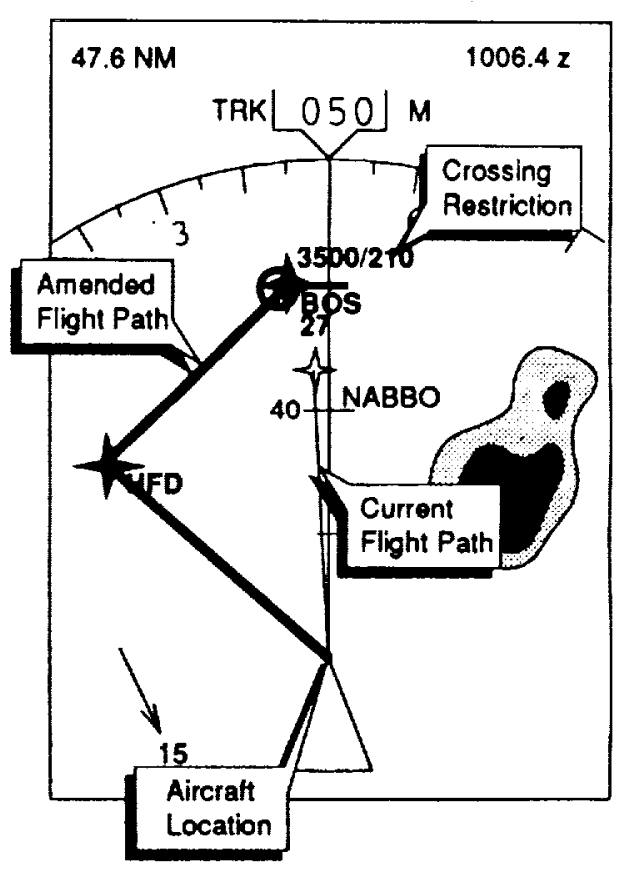

Flgure 8: Graphical ATC Route Amendment. The bold line represents a new routing delivered by digital datalink; it nashes until accepted or rejected by the pilot. 


\section{CONCLUSIONS}

A part-lask advanced cockpit simulator has been developed to evaluate the effect of advanced cockpit information management systems on pilot cognitive performance. The utility of this part-task approach for rapid preliminary evaluation of new graphical displays and new datalink applications has been demonstrated through a series of successful experiments.

The MIT Advanced Cockpit Simulator replicates the major autoflight and electronic flight instrumentation systems of a modern "glass-cockpit" transport aircraft, but does not include manual flight controls or a cockpit mock-up. This simplicity reduces set-up time, cost, and allows the facility to be easily moved. Since the simulator is based on a commercially-available graphics workstation, it can be rapidly reconfigured and does not require special hardware. In order to maximize the validity of the results. the subject pool is limited to professional air carrier pilots currently qualified on "glass-cockpit" aircraft.

Concepts evaluated using this simulator include graphical microburst alerting displays, electronic instrument approach plates, terrain awareness and alerting displays, and ATC routing amendment delivery through digital datalinks. Topics for future experiments include HUDs, displays for airborne forward-looking wind shear sensors, and continued study of terrain avoidance displays and issues associated with digital ground-air datalinks.

\section{ACKNOWLEDGEMENTS}

Support for the research activities discussed above was received from the Federal Aviation Administration. National Aeronautics and Space Administration, DOT Volpe National Transportation Systems Center, Lincoln Laboratory, and the National Science Foundation Presidential Young Investigator Award Program under the following grants; MSS-8552702, NGL-22-009-640, BARR-10-119, NAG 2-12, NAG 2-716, DTRS 57-88-C-0078TD39. NAG-1-690. The simulation activities were aided by cooperation of the Air Line Pilots Association, the Allied Pilots Association, American Airlines, Delta Airlines, and United Airlines. The authors would especially like to thank the many subject pilots who participated in the experiments.

\section{REFERENCES}

[1] Hinton, David A., Relative Merits of Reactive and Forward-Look Detection for Wind-Shear Encounters During Landing Approach for Various Microburst Escape Strategies, NASA TM-4158, DOT/FAA/DS-89/35. February, 1990.

[2] Personal Communication with Arun Nadkami, Boeing Commercial Airplane Company, August 1988.

[3] Oseguera, Rosa M. and Bowles, Roland L., A Simple Analytic 3-Dimensional Model Based on Boundary Layer Slagnation Flow. NASA TM-100632, NASA Langley Research Center, Hampton, VA, July 1988.

[4] Kuchar. J.K., 'MAP' - Electronic Approach Plate Protoryping Software Documentation, MIT Aeronautical Systems Laboratory Report ASL-90-6. October 1990.
[5] Wanke, C., and Hansman, R. J., "Experimental Evaluation of Candidate Graphical Microburst Alert Displays," AIAA Paper 92-0292, 30th Aerospace Sciences Meeting \& Exhibit. Reno. NV. January 1992.

[6] Mykityshyn, M. and Hansman, R.J., An Exploratory Suriey of Information Requirements For Instrument Approach Charts, MIT Aeronautical Systems Laboratory Report ASL-90-1-2, November 1990.

[7] Kuchar, J., and Hansman, R J.. Advanced Terrain Displays for Transport Calegory Aircrafi. MIT Aeronautical Systems Laboralory Report. ASL-91-3. August 1991.

[8] Hahn, E. and Hansman, R.J., "Experimental Studies on the Effect of Automation on Pilot Situational Awareness in the Datalink ATC Environment," SAE Aerospace Technology Conference and Exposition '92, Anaheim, CA, (to be presented October 1992). 
